\title{
Trait Correlates of Success at Work
}

\author{
Alexandra Teodorescu ${ }^{1}$ \\ Adrian Furnham ${ }^{1,2}$ \\ Ian MacRae ${ }^{1}$
}

${ }^{1}$ Research Department of Clinical, Educational and Health Psychology, University College London26 Bedford Way, London WC1 0AP, London

${ }^{2}$ Norwegian Business School (BI), Nydalveien, Olso, Norway.

Contact Details of corresponding author: : a.furnham@ucl.ac.uk

Abstract 
Purpose: Identifying and developing high potential individuals is fundamental to successful companies and organisations. The present study focuses on the personality traits of high potential individuals.

Design: The High Potential Traits Inventory (MacRae, 2012; MacRae \& Furnham, 2014) was used to investigate associations between personality traits and subjective and objective measures of career success, in a sample of 383 employed individuals.

Findings: Results indicate High Potential Traits Inventory (HPTI) personality traits relate to subjective and objective measures of success with Conscientiousness being the strongest predictor. The findings of the current study are consistent with previous research on High Flyers.

Implications: Implications of the current study are discussed, suggesting a clearer operationalization of success is crucial for understanding the underlying mechanisms which lead from personality to potential.

Originality/Value: This the validation of a new, robust and succinct measure designed to identify High Flyers in the workplace.

\section{Introduction}

Every organisation attempts to find and develop individuals who have the potential for success and achievement and thus to provide value to the organisation. One major challenge in the process of identifying, developing and retaining high potential individuals has been the lack of a clear understanding and operational definition of potential in the workplace. Silzer and Church (2009a) conducted a survey across different organisations and definitions of potential vary greatly between companies. Silzer and Church (2009b) argued potential could be better 
understood through seeking answers to the question, "potential to do what?" which helps distinguish between different types of potential, such as potential for technical aptitude, leadership capacity or sales ability.

A measure of potential at work often attempts to measure the stable characteristics that predict success in any sector/department while being mindful of differences affecting performance such as skills, motivation and experience. Based on Silzer and Church's (2009b) theoretical framework of potential, MacRae and Furnham (2014) have developed the High Potential Traits Inventory (HPTI) a measure of personality traits directly relevant to workplace behaviours, thoughts and perceptions of the self and others at work. The HPTI can be used to investigate which personality traits in the workplace might predict career success and thus predict high potential (MacRae \& Furnham, 2014).

\section{High Potential Personality Traits}

Personality describes the "fundamental, consistent aspects of how a person thinks and reacts emotionally, and how those reactions influence behaviour" (MacRae \& Furnham, 2014). The most widely used personality measure is Costa and McCrae's (1992) Big Five model, which assesses five personality traits. While numerous studies with the Big Five model have found consistent relationships between personality and career success, the model is not a specific model of personality to the workplace, and some of its factors, specifically Agreeableness, have consistently failed to predict job performance (Barrick, Mount \& Judge, 2001; Judge, Higgins, Thoresen \& Barrick, 1999).

Based on Silzer and Church's (2009b) framework for potential, the High Potential Traits Inventory (MacRae, 2012; MacRae \& Furnham 2014) was designed to provide an accurate, valid and clear measure of personality at work. Originally composed of ten factors and characteristics related to success and leadership capability, the traits were recombined into 
six common factors (MacRae, 2012), which are most relevant for the workplace using Factor Analysis and Structural Equation Modelling.

\section{Career Success: Objective and Subjective measures}

Career success is defined as "the accumulated positive work and psychological outcomes resulting from one's work experiences” (Seibert, Kraimer \& Liden, 2001). In research, success has previously been operationalized as objective and subjective career success (Furnham, 2017). Objective success refers to extrinsic indicators of success, which can be evaluated objectively by others, such as annual income and number of promotions (Judge, Cable, Boudreau \& Bretz, 1995). Subjective, or intrinsic, measures of career success attempt to capture an individual's subjective judgments about their career achievements and typically include self-report measures such as job or career satisfaction (Barrick et al., 2001; Judge et al., 1999).

Most research on personality and career success has been conducted using Costa and McCrae's (1992) Big Five model of personality. Three of the Big Five personality traits have been consistently linked to career success, namely Conscientiousness, Neuroticism (low Adjustment) and Openness to Experience (Curiosity) (Judge et al., 1999; Ng, Eby, Sorensen \& Feldman, 2005; Tett, Jackson \& Rothstein, 1991). A meta-analysis of the Big five personality traits and career success found Conscientiousness to be the strongest and most consistent predictor of career success across occupations and all measures of success (Barrick et al., 2001). Neuroticism (Low adjustment) has been found to negatively relate to job performance, as low reactivity to stress and anxiety may reduce both career satisfaction and effective career management, leading to poor performance (Judge et al., 1999; Ng et al., 2005; Seibert et al., 2001). Barrick et al. (2001) found that Openness to Experience (Curiosity) was less associated to job performance than Conscientiousness or Neuroticism. However, Curiosity may still be 
useful for identifying potential if made more relevant to the workplace such as openness to new ideas and approaches instead of aesthetic appreciation and emotionality.

\section{This Study}

The purpose of the current study was to further examine the relationship between HPTI personality traits and objective and subjective measures of career success. Based on previous research on personality and career success, the hypotheses for the present study are:

H1: Conscientiousness, Adjustment, Curiosity, Ambiguity Acceptance, Courage and Competitiveness will positively relate to both subjective and objective measures of career success, with Conscientiousness being the strongest predictor.

$\mathrm{H} 2$ : Objective and subjective measures of career success will positively correlate with one another.

\section{Method}

\section{Participants}

In all 383 participants took part in the current study where they were asked to complete an online version of the High Potential Traits Inventory (MacRae \& Furnham, 2014).

Participants' age ranged from 18 to 66 , with a mean age of $40.5(S D=10.49)$. The gender balance was nearly equal in the sample, with $53.3 \%$ male $(N=204), 43.9 \%$ female $N=168)$ and $2.9 \%(N=11)$ did not report their gender. Participants are working professionals from international organisations, who were recruited individually through a range of online methods and professional networks by the current investigators, eliminating any concerns with regards to any direct workplace effects/impact of the assessment results. The sample was international, with the majority of the sample living in the UK (53.8\%), 9.4\% lived in Singapore, $8.6 \%$ were from South Africa, $7.3 \%$ lived in the UAE, and the remaining $20.9 \%$ lived in other countries 
or did not report their country of residence. Participants reported their occupation using the Canadian National Occupation Codes (NOC), including Management (57.7\%), Business and Finance (12.8\%), Social and Government services (12\%) and Health (4.7\%). Participants' income ranged from $£ 11,000$ to $£ 261,000(M=£ 69,000.00, S D=£ 40,600.00)$.

\section{Measures}

High Potential Traits Inventory

The High Potential Traits Inventory was developed to measure personality factors associated with success and high performance in the workplace (MacRae, 2012; MacRae \& Furnham, 2014). It consists of six factors which are assessed through a 78-item self-report questionnaire. Examples of questions include, "My personal targets at work exceed those that the organization (e.g., school, company, social clubs) would set for me" (Conscientiousness) and "I get frustrated when I don't know precisely what's expected of me at work" (Ambiguity Acceptance).

\section{Subjective and Objective measures of Success}

Five subjective measures of career success were assessed as follows: General Success - "I am generally very successful"; Success with Promotions - "I do not get promoted as quickly as my colleagues"; Success in Education - "I was/am very successful in education"; Success with Marks - "In education, I tend(ed) to receive higher marks than my peers"; Success at Work- "I am very successful in my line of work". Participants' responses were measured on a 7-point Likert scale, as with the HPTI. Participants were also prompted to report three objective measures of career success, annual income, time since last pay rise and time since last promotion in months. Participants were asked about the most recent promotion rather than the 
number of promotions in one's career in order to avoid age bias, as older individuals generally will have had more promotions.

\section{Procedure}

All participants completed the HPTI online. Subjective and Objective measures of success were also assessed by asking participants to rate their own success and reported time since their last pay rise, last promotion and current income. The study took 15-20 minutes to complete and participants received a detailed report with summary of their results. They were provided with contact information should they wish to discuss their results in further detail.

\section{Results}

Insert Table 5 here

\section{Correlations: HPTI Scores and Success}

Bivariate correlations were computed to investigate the relationships between the personality traits and measures of success (see Table 1). As predicted, Conscientiousness was most strongly correlated with measures of subjective success, which is consistent with previous findings on the relationship between personality and job performance (Barrick et al., 2001; MacRae \& Furnham, 2014) and with the current hypothesis. Adjustment, Ambiguity Acceptance, Curiosity, Competitiveness and Courage were also moderately correlated with self-reported measures of subjective success. Success at work significantly correlated with all of the HPTI traits and Success with promotions also correlated significantly with all but one of the HPTI factors, Ambiguity Acceptance. These results provide insight into the links between HPTI traits and success in the workplace. 
Success in education and high marks did not show strong correlations with any of the HPTI traits, but were highly correlated with each other. Interestingly, two of the objective measures of success (time since last pay rise and time since last promotion) did not correlate with any of the personality factors, nor with the subjective measures of success. One possible explanation for these findings is that the economic climate at the time the data were gathered means many organizations had implemented pay freezes.

Self-reported measures of subjective success demonstrated relatively high internal reliability (5 items; $a=.66$ ) and were combined into one measure, named Subjective success, for further analysis. Cronbach's alpha value for the measures of objective success was too low to allow the measures to be combined into one Objective Success measure. All measures of success were converted to z-scores and summed to create an Overall Success measure, which was used to further investigate the relationship between the HPTI traits and success. As presented in Table 6, both Subjective Success and the Overall success measures correlate the strongest with Conscientiousness, providing further support for the first experimental hypothesis. Furthermore, moderately strong associations between success and the HPTI traits can be observed as all personality measures significantly correlate with Subjective Success. Overall Success correlated significantly with all personality traits except for Curiosity.

Insert Table 2 here

\section{Stepwise Regression Analyses}

To further investigate the relationship between the HPTI traits and measures of success, stepwise regression analyses were computed. Demographics were included at Step 1 of the model to account for any differences that may arise due to age and gender. These predicted only $0.4 \%$ of the variance, and were not significant predictors of Subjective Success $(F(2,373)$ 
$=.80, p>.05)$. Conscientiousness was revealed as the strongest predictor of Subjective Success, explaining an additional $9.2 \%$ of the variation in Subjective Success $(F(1,37)=37.64$, $p<.001)$. At the last stage, the model included age, gender, Conscientiousness, Competitiveness, Adjustment and Ambiguity Acceptance, where age and gender became once again non-significant predictors of Subjective Success as presented in Table 2. At Step 5, the model accounted for $15.8 \%$ of the variation in Subjective Success $(F(6,373)=11.45, p<$ $.001)$

Insert Table 3 here

Stepwise regression analyses were also computed to investigate any predictors of measures of objective success. The results from Table 3 suggest the HPTI traits cannot explain a significant amount of variance in time since last promotion and time since last pay rise. These results may have been, however, affected by issues in the data representing the objective measures of success. Interestingly, age and gender are significant predictors of both time since last promotion and time since last pay rise accounting for $19.8 \%$ of the variance in time since last promotion $(F(2,307)=37.74, p<.001)$ and $6.6 \%$ of the variance in time since last pay rise $(F(2,316)=11.10, p<.001)$. Stepwise regression revealed that age and gender contributed significantly to the variation in income, by explaining $20.3 \%$ of the variance $(F(2,299)=38.02$, $p<.001)$. At the last stage, the model included age, gender, Competitiveness and Ambiguity Acceptance as predictors of income, explaining $25.9 \%$ of the total variance $(F(4,301)=25.90$, $p<.05)$, with gender becoming a non-significant predictor at this step.

Insert Table 4 here 
Lastly, a stepwise regression analysis was conducted with Overall Success as the dependent measure (see Table 4). Age and gender were entered at Stage 1 and revealed a significant contribution to the regression model, accounting for $11.1 \%$ of the total variance $(F(2,262)=16.40, p<.001)$. At Step 2, Conscientiousness accounted for an additional $6.3 \%$ of the variation in Overall Success, and this change in $R^{2}$ was significant $(F(1,261)=19.82, p$ $<.001)$. The final model explained $19.5 \%$ of the variation in Overall Success, and included age, gender, Conscientiousness and Competitiveness, although at this stage, gender was no longer a significant predictor of Overall Success.

\section{Insert Table 5 here}

\section{Gender and age effects on HPTI Traits and on Measures of Success}

One-Way ANOVAs were computed to determine any effects of gender on the HPTI traits. Males reported slightly higher Courage than females, $(F(2,380)=9.02, p<.001)$, but no other significant gender differences were identified in the HPTI traits. Men reported slightly higher levels of Success with Promotion, $F(2,382)=3.81, p<.05)$, as well as in Success at Work, $F(2,379)=, p<.05)$. Women reported shorter times (in months) since having last been promoted, $F(2,307)=5.11, p<.01)$, as well as shorter times since having last received a pay rise, although this difference was not statically significant. Men reported higher levels of income, $F(2,301)=5.86, p<.01)$ with $£ 76,000$ as the mean income for males, and $£ 60,000$ as the mean income for females. Lastly, men reported a slightly higher level of Overall Success, $F(2,264)=4.94, p<.01$

To examine age effects on the HPTI traits, one-way ANOVAs were conducted which revealed a significant age effect on Adjustment $(F(45,373)=1.76, p<.01)$, as well on Ambiguity Acceptance $F(45,373)=2.06, p<.001)$ and Courage $(F(45,373)=1.76, p<.05)$. 
Significant age effects were identified for time since last having been promoted, $F(44,307)=$ $7.25, p<.001)$, and time since last having received a pay rise, $F(44,316)=2.05, p<.001)$. Figures 1 and 2 reveal longer times since last promotion in older individuals. Income was also significantly influenced by age, $F(43,301)=3.39, p<.001)$ as increases in age revealed higher income. Lastly, a significant age effect was also identified for Overall Success, $F(43,264)=$ $1.70, p<.01)$.

\section{Discussion}

Personality traits correlated the strongest with measures of subjective success, particularly with those most relevant in the workplace, namely General Success, Success with Promotions, and Success at Work. Correlations between the personality traits and the objective measures of success were mostly non-significant for time since last promotion and time since last pay rise, but were slightly stronger for income. Positive correlations between the objective and subjective measures of success were also predicted in the second hypothesis.

While subjective measures of success positively correlated with each other, only weak correlations were observed between the objective and subjective measures of career success. Time since last pay rise and time since last promotion did not correlate significantly with any of the subjective success measures, but income was moderately correlated with both Success with Promotions and Success at Work. While some of the results may have been affected by poor operationalization of success measures, the findings of the current study are largely consistent with previous research on personality and performance (Barrick et al., 2001; MacRae, 2012; Ng et al., 2005).

Correlations between the HPTI traits and subjective measures of career success provided strong support for the first hypothesis. All personality traits correlated significantly with General Success and Success at Work. Success with Promotions correlated significantly 
with all personality traits except Ambiguity Acceptance. While Success in Education and Success and High Marks were strongly correlated with each other, no significant correlations of the two with the personality traits were identified. The self-reported measures showed strong internal reliability and were combined into one overall measure of Subjective Success, which revealed significant positive correlations with all of the HPTI Traits. These findings are consistent with previous research on personality and subjective measures of success ( $\mathrm{Ng}$ et al., 2005). A step-wise regression analysis for Subjective Success revealed that Conscientiousness, Competitiveness, Adjustment and Ambiguity Acceptance predict $15.8 \%$ of the total variation, with Conscientiousness alone accounting for $9.2 \%$ of the variance. Conscientiousness was identified as the strongest predictor of Subjective Success, which is consistent with the first hypothesis and with previous findings, making Conscientiousness the central component of the HPTI, consistent with findings from Barrick et al. (2001) and MacRae (2012).

Correlations between the HPTI personality traits and objective measures of success revealed considerably different results from those with the subjective success measures. No significant correlations were identified between the personality traits and two of the objective measures of career success: time since last pay rise and time since last promotion. However, moderate correlations were found between income and three of the HPTI factors: Competitiveness, Ambiguity Acceptance and Courage.

Unlike the subjective measures, the internal reliability between the three objective measures of success was extremely low, suggesting these measures are conceptually distinct and may be predicted by different factors. Based on these findings, an overall measure of objective career success was not computed and regression analyses were conducted for each of the three objective measures of success separately. Step-wise regression analyses for time since last pay rise and time since last promotion revealed none of the HPTI traits were significant predictors of objective success, with age and gender accounting for $6.6 \%$ of the variance in 
time since last pay rise and $19.8 \%$ of the total variation in time since last promotion. A stepwise regression was also conducted for income, which revealed two of the HPTI traits as significant predictors, with Competitiveness and Ambiguity Acceptance explaining 25.9\% of the total variation in income alongside age and gender.

Analyses examining the relationship between personality and objective measures of success provide partial support for the first hypothesis, as two of the HPTI traits were revealed as significant predictors of income. However, the first hypothesis did not receive full support based on the non-significant associations between the HPTI traits and the other two objective measures of success. One possible explanation for these findings is the poor operationalization of success measures. This has led to a lack of consistency of the construct in the literature, which has crucial implications for the generalisation of these findings (MacRae \& Furnham, 2014; Ng et al., 2005). Furthermore, there are certain problems associated with asking participants to provide information about their annual salary, pay rise and promotions, as it may make some feel uncomfortable, or unwilling to share such sensitive information, even when informed of the anonymity of their results.

The second hypothesis predicted positive correlations between the subjective and objective measures of career success. In general, subjective measures of success showed high correlations with each other and high internal reliability. Objective measures of success revealed much weaker correlations with each other. Time since last promotion was moderately correlated with both time since last pay rise and income, but no significant correlation was found between time since last pay rise and income. Therefore, the objective measures of success could not be combined into an overall objective measure because of the low internal reliability. Correlations between objective and subjective measures were also relatively low, with only income revealing significant correlations with subjective measures of success, specifically with Success at Work and Success with Promotions. Despite the weak correlations 
between some of the measures of success, an overall measure of career success was computed and used for exploratory analysis with the HPTI Traits.

While the results of the current study provide only partial support for the second experimental hypothesis, they are consistent with previous findings. Following their experiment on personality and career success, $\mathrm{Ng}$ et al. (2005) argue objective and subjective measures of success may be conceptually distinct as evidenced by the weak correlations between each other, and proposed they may be predicted by different factors. Ng et al. (2005) suggest personality traits may be more relevant for predicting subjective measures of success which are more strongly associated to psychological well-being and personal assessment, while human capital and demographics may be better predictors of objective measures of success.

One limitation of the present study, and of much of the research in this field is the lack of clear operationalization of measures of success. The self-reported success measures are a further limitation of the study. Subjective, or intrinsic, measures of career success attempt to capture an individual's subjective judgements about their career achievements and typically include self-report measures such as job or career satisfaction (Judge et al., 1999; Barrick et al., 2001). While objective measures of success such as annual income and number of promotions (Judge et al., 1995) can be obtained from the organisation's archives, it is common in I/O research to also assess these measures of success via self-report measures. Furthermore, as participants of the present study come from multiple organisations and geographical areas, we argue the value added and the generalizability of our current findings, albeit via selfreported measures, for these participants is greater than that of a homogenous sample from one organisation.

Implications/ Value added 
In today's ever-changing environment where each organisation must constantly adapt in order to survive, selection, development and retention of high potential employees who are able to add value to the organisation has become a critical strategy for competitive advantage. To successfully identify high flyers, organisations must first have a clear understanding and operationalization of potential. Based on Silzer and Church's (2009b) framework for potential, the HPTI (MacRae and Furnham, 2014) is a robust measure of personality traits directly relevant to workplace behaviours. The current study has used the HPTI to investigate which of these personality traits might be used to predict career success, and in turn, high potential. The current findings further demonstrate that the HPTI is a reliable and well-validated measure of personality at work, with a sound theoretical foundation. Following the further validation of the HPTI and establishing its relationship to both objective and subjective measures of career success, we conclude that the HPTI can provide organisations with an effective tool in selection, and when combined with robust motivational and cognitive ability tools, it can be a valuable resource throughout the employment cycle. 


\section{References}

Barrick, M. R., Mount, M. K., \& Judge, T. A. (2001). Personality and performance at the beginning of the new millennium: What do we know and where do we go next?. International Journal of Selection and Assessment, 9, 9-30.

Costa, P. T., \& McCrae, R. R. (1992). Four ways five factors are basic. Personality and individual differences, 13(6), 653-665.

Furnham, A. (2017). Personality and Occupational Success. In Virgil Zeigler-Hill \& Todd K. Shackelford (Eds). The SAGE Handbook of Personality and Individual Differences. New York: Sage.

Human Resources and Skills Development Canada (2011). National Occupational Classification 2011.http://www5.hrsdc.gc.ca/NOC/English/NOC/2011/Welcome.aspx

Judge, T. A., Cable, D. M., Boudreau, J. W., \& Bretz, R. D. (1995). An empirical investigation of the predictors of executive career success. Personnel Psychology, 48(3), 485-519.

Judge, T. A., Higgins, C. A., Thoresen, C. J., \& Barrick, M. R. (1999). The big five personality traits, general mental ability, and career success across the life span. Personnel Psychology, 52(3), 621-652.

MacRae, I. (2012). Success, potential and validating a measure of High Flying Personality Traits in Organisations. Unpublished Thesis. University College London.

MacRae, I., \& Furnham, A. (2014). High Potential: How to spot, manage and develop talented people at work. London: Bloomsbury.

Ng, T. W., Eby, L. T., Sorensen, K. L., \& Feldman, D. C. (2005). Predictors of objective and subjective career success: A meta-analysis. Personnel Psychology, 58(2), 367-408.

Seibert, S. E., Kraimer, M. L., \& Liden, R. C. (2001). A social capital theory of career success. Academy of Management Journal, 44(2), 219-237. 
Silzer, R., \& Church, A. H. (2009a). Identifying and assessing high potential talent: Current organizational practices. In R. F. Silzer, \& B. E. Dowell (Eds.) Strategy-driven talent management: A leadership imperative. Jossey Bass, San Francisco, CA, pp. 213-81.

Silzer, R., \& Church, A. H. (2009b). The pearls and perils of identifying potential. Industrial and Organizational Psychology, 2(4), 377-412.

Tett, R. P., Jackson, D. N., \& Rothstein, M. (1991). Personality measures as predictors of job performance: a meta-analytic review. Personnel Psychology, 44(4), 703-742.

Table 1

Correlation matrix between HPTI traits and measures of Success 


\begin{tabular}{|c|c|c|c|c|c|c|c|c|c|c|c|c|c|c|c|c|}
\hline & 1 & 2 & 3 & 4 & 5 & 6 & 7 & 8 & 9 & 10 & 11 & 12 & 13 & 14 & 15 & 16 \\
\hline 1. Adjustment & - & & & & & & & & & & & & & & & \\
\hline 2. Curiosity & $.20^{* *}$ & - & & & & & & & & & & & & & & \\
\hline 3.AmbiguityAcce & $.34^{* *}$ & $.38^{* *}$ & - & & & & & & & & & & & & & \\
\hline 4.Conscientiousne & $.28^{* *}$ & $.29^{* *}$ & $.13^{*}$ & - & & & & & & & & & & & & \\
\hline 5.Competitiveness & $-.12^{*}$ & $.17^{* *}$ & -.01 & $.31^{* *}$ & - & & & & & & & & & & & \\
\hline 6. Courage & $.44^{* *}$ & $.51^{* *}$ & $.48^{* *}$ & $.48^{* *}$ & $.19^{* *}$ & - & & & & & & & & & & \\
\hline 7. Success General & $.27^{* *}$ & $.13^{*}$ & $.15^{* *}$ & $.24^{* *}$ & $.21^{* *}$ & $.27^{* *}$ & - & & & & & & & & & \\
\hline 8.Success Promote & $.17^{* *}$ & $.17^{* * *}$ & .06 & $.26^{* *}$ & $.25^{* *}$ & $.22^{* *}$ & $.29^{* *}$ & - & & & & & & & & \\
\hline 9.SuccessEducatio & .04 & $.11^{*}$ & .10 & .09 & .08 & .02 & .05 & $.35^{* *}$ & - & & & & & & & \\
\hline 10. Success Marks & -.02 & .04 & .08 & .08 & .10 & -.01 & .02 & $.22^{* *}$ & $.78^{* *}$ & - & & & & & & \\
\hline 11. Success Work & $.31^{* *}$ & $.18^{* * *}$ & $.19^{* *}$ & $.39^{* *}$ & $.18^{* *}$ & $.29^{* *}$ & $.29^{* * *}$ & $.61^{* *}$ & $.28^{* * *}$ & $.21^{* *}$ & - & & & & & \\
\hline 12.Lastpromotion ${ }^{\mathrm{a}}$ & .02 & -.07 & .06 & .01 & -.11 & .05 & -.06 & -.01 & -.09 & -.09 & -.01 & - & & & & \\
\hline 13. Last pay rise ${ }^{b}$ & .06 & -.02 & -.01 & .05 & -.08 & .06 & -.02 & -.05 & -.01 & -.05 & .00 & $.27^{* *}$ & - & & & \\
\hline 14. Income & .03 & .00 & $.26^{* *}$ & .06 & $.11^{*}$ & $.17^{* *}$ & .10 & $.18^{* *}$ & .05 & .04 & $.19^{* * *}$ & $.20^{* *}$ & .03 & - & & \\
\hline 15.SubjectiveSucc & $.22^{* *}$ & $1.8^{* *}$ & $.19^{* *}$ & $.30^{* *}$ & $.23^{* *}$ & $.22^{* *}$ & $.52^{* *}$ & $.68^{* *}$ & $.75^{* *}$ & $.68^{* *}$ & $.66^{* *}$ & -.08 & -.04 & $.14^{*}$ & - & \\
\hline 16.OverallSuccess & $.17^{* *}$ & .11 & $.21^{* *}$ & $.28^{* * *}$ & $.16^{* *}$ & $.26^{* *}$ & $.40^{* *}$ & $.67^{* *}$ & $.63^{* *}$ & $.57^{* *}$ & $.62^{* *}$ & $.85^{* *}$ & $.32^{* * *}$ & $.33^{* *}$ & $.85^{* *}$ & - \\
\hline
\end{tabular}


Table 2

Correlations between HPTI traits, Subjective Success and Overall Success

\begin{tabular}{lllllllll}
\hline & 1 & 2 & 3 & 4 & 5 & 6 & 7 & 8 \\
\hline 1. Adjustment & - & & & & & & \\
2. Curiosity & $.20^{* *}$ & - & & & & & \\
3. Ambiguity Acceptance & $.34^{* *}$ & $.38^{* *}$ & - & & & & & \\
4. Conscientiousness & $.28^{* *}$ & $.29^{* *}$ & $.13^{*}$ & - & & & & \\
5. Competitiveness & $-.12^{*}$ & $.17^{*}$ & -.01 & $.31^{* *}$ & - & & \\
6. Courage & $.44^{* *}$ & $.51^{* *}$ & $.48^{* *}$ & $.48^{* *}$ & $.19^{* *}$ & - & & \\
7. Subjective Success & $.22^{* *}$ & $.18^{* *}$ & $.19^{* *}$ & $.30^{* *}$ & $.23^{* *}$ & $.22^{* * *}$ & - & \\
8. Overall Success & $.17^{* *}$ & .11 & $.21^{* *}$ & $.28^{* *}$ & $.26^{* *}$ & $.22^{* *}$ & $.85^{* *}$ & -
\end{tabular}

Note. $* p<0.05, * * p<0.01$ 
Table 3

Stepwise regression for predicting the effects of HPTI traits on Subjective Success

\begin{tabular}{|c|c|c|c|}
\hline Variable & $b$ & $S E b$ & $\beta$ \\
\hline \multicolumn{4}{|l|}{ Step 1} \\
\hline Age & .00 & .00 & .04 \\
\hline Gender & -.08 & .08 & -.05 \\
\hline \multicolumn{4}{|l|}{ Step 2} \\
\hline Age & .00 & .00 & .01 \\
\hline Gender & -.07 & .08 & -.04 \\
\hline Conscientiousness & 22.54 & 3.68 & $.31 * * *$ \\
\hline \multicolumn{4}{|l|}{ Step 3} \\
\hline Age & .00 & .00 & .05 \\
\hline Gender & -.03 & .08 & -.02 \\
\hline Conscientiousness & 18.41 & 3.87 & $.25^{* * *}$ \\
\hline Competitiveness & .17 & .39 & $.25 * *$ \\
\hline \multicolumn{4}{|l|}{ Step 4} \\
\hline Age & .00 & .00 & .03 \\
\hline Gender & -.02 & .08 & -.01 \\
\hline Conscientiousness & 14.01 & 4.02 & $.19 * *$ \\
\hline Competitiveness & .20 & .05 & $.20 * * *$ \\
\hline Adjustment & -.18 & .05 & $.18^{* *}$ \\
\hline \multicolumn{4}{|l|}{ Step 5} \\
\hline Age & .00 & .00 & .00 \\
\hline Gender & -.01 & .80 & -.01 \\
\hline Conscientiousness & 13.99 & 4.00 & $.19^{* *}$ \\
\hline Competitiveness & .20 & .05 & $.20 * * *$ \\
\hline Adjustment & -.14 & .05 & $.14^{*}$ \\
\hline Ambiguity Acceptance & .12 & .48 & $.12 *$ \\
\hline
\end{tabular}

Step $5 . * p<.05, * * p<.01,{ }^{* * *} p<.001$. 
Table 4

Stepwise regression for predicting the effects of HPTI personality traits on measures of Objective Success

\begin{tabular}{|c|c|c|c|c|c|c|c|c|c|}
\hline \multirow[b]{2}{*}{ Variable } & \multicolumn{3}{|c|}{ Last promotion $^{\mathrm{a}}$} & \multicolumn{3}{|c|}{ Last pay rise $^{\mathrm{b}}$} & \multicolumn{3}{|l|}{ Income } \\
\hline & $b$ & $S E b$ & $\beta$ & $B$ & $S E b$ & $\mathrm{~b}$ & $b$ & $S E b$ & $\beta$ \\
\hline \multicolumn{10}{|l|}{ Step 1} \\
\hline Age & 1.13 & .14 & $.42 * * *$ & .27 & .06 & $.25 * * *$ & 1628.32 & 204.52 & $.41 * * *$ \\
\hline Gender & -5.05 & 2.60 & $-.10 *$ & -1.05 & 1.09 & -.05 & -9970.49 & 3879.09 & $-.13 *$ \\
\hline \multicolumn{10}{|l|}{ Step 2} \\
\hline Age & & & & & & & 1769.67 & 204.91 & $.45 * * *$ \\
\hline Gender & & & & & & & -7933.97 & 3853.92 & $-.17 *$ \\
\hline Competitiveness & & & & & & & 8187.20 & 2355.28 & $.18 *$ \\
\hline \multicolumn{10}{|l|}{ Step 3} \\
\hline Age & & & & & & & 1623.70 & 207.14 & $.41 * * *$ \\
\hline Gender & & & & & & & -7298.86 & 3802.66 & -.10 \\
\hline Competitiveness & & & & & & & 8005.39 & 2321.41 & $.18 * *$ \\
\hline Ambiguity & & & & & & & 6592.33 & 2089.95 & $.162 *$ \\
\hline \multicolumn{10}{|c|}{ Acceptance } \\
\hline \multicolumn{10}{|c|}{ Note. ${ }^{*} p<.05 . * * p<.01,{ }^{*} * *<.001 ;$ Last promotion: $R^{2}=.20(\mathrm{ps}<.05) ;$ Last pay rise: $R^{2}=.67 ;$ Income: $R^{2}$} \\
\hline \multicolumn{10}{|c|}{ atime since last promotion in months } \\
\hline
\end{tabular}

\section{Table 5}

Stepwise regression for predicting the effects of HPTI traits on Overall Success

\begin{tabular}{llll}
\hline Variable & $b$ & $S E b$ & $\beta$ \\
\hline Step 1 & & &
\end{tabular}




\begin{tabular}{|c|c|c|c|}
\hline Age & .12 & .02 & $.29 * * *$ \\
\hline Gender & -.86 & .44 & $-.12 *$ \\
\hline \multicolumn{4}{|l|}{ Step 2} \\
\hline Age & .11 & .02 & $.27 * * *$ \\
\hline Gender & -.84 & .42 & $-.11 *$ \\
\hline Conscientiousness & 84.422 & 18.422 & $.25 * * *$ \\
\hline \multicolumn{4}{|l|}{ Step 3} \\
\hline Age & .12 & .02 & $.31 * * *$ \\
\hline Gender & -.65 & .42 & -.09 \\
\hline Conscientiousness & 68.88 & 19.66 & $.21 * *$ \\
\hline Competitiveness & .73 & .28 & $.16^{* *}$ \\
\hline
\end{tabular}

